\title{
CONTRIBUIÇÕES DA PEDAGOGIA HISTÓRICO-CRITÍCA À FORMAÇÃO E ORGANIZAÇÃO DO TRABALHO DOCENTE NA EDUCAÇÃO INFANTIL
}

\author{
Madma Laine Colares Gualbertol \\ Juracy Machado Pacífico²
}

\begin{abstract}
RESUMO
O estudo consiste em compreender as contribuições da Pedagogia Histórico-Crítica para o processo de formação de professores da educação infantil e para a organização do trabalho docente, considerando seus fundamentos filosóficos, psicológicos e pedagógico-didáticos. Apresenta a articulação dialética desta teoria com a práxis. A metodologia é de caráter bibliográfico e contempla os pressupostos do Materialismo histórico-dialético e da Pedagogia Histórico-Crítica a partir de Marx (1984; 1985), Saviani (2000; 2008; 2011; 2013), Arce e Martins (2013), Marsiglia (2011), Colares (2011), Duarte (1999; 2007; 2016) e Pasqualini (2011). Os resultados permitem concluir que os fundamentos da Pedagogia Histórico-Crítica corroboram o planejamento e desenvolvimento da prática educativa que considere a tríade "destinatário-conteúdo-forma" com a valorização do papel exercido pelo professor de educação infantil para produzir, de maneira intencional, em cada indivíduo, a humanidade que é constituída histórica e coletivamente pelos seres humanos com a apropriação do conhecimento cultural e socialmente produzido.
\end{abstract}

Palavras-chave: Pedagogia histórico-crítica. Formação de professores. Educação Infantil.

\section{CONTRIBUTIONS OF HISTORICAL-JUDICIOUS PEDAGOGY TO THE FORMATION} AND ORGANIZATION OF TEACHING WORK IN EARLY CHILDHOOD EDUCATION

\begin{abstract}
1 Doutoranda em Educação na Amazônia, Polo Santarém-Pará-Brasil, Universidade Federal do Oeste do Pará (Ufopa), turma 2021. Orcid iD: https://orcid.org/0000-0001-7794-0269. Email: madma_laine@hotmail.com

2 Professora da Universidade Federal de Rondônia - UNIR, Brasil, Departamento de Ciências da Educação - DACED e Programa de Pós-Graduação em Educação Escolar, Mestrado e Doutorado Profissional - PPGEEProf e Doutorado em Educação na Amazônia, Polo Santarém. Líder do Grupo EDUCA - Grupo de Pesquisa Multidisciplinar em Educação e Infância e Grupo GEPEIN - Grupo de Estudos e Pesquisas em Educação Infantil, Infância e Educação Especial e Inclusiva. É Editora da Revista EDUCA - Revista Multidisciplinar em Educação. Orcid iD: https://orcid.org/0000-0003-0486-874X.E-mail: juracypacifico@unir.br
\end{abstract}


The study consists of understanding the contributions of The Historical-Critical Pedagogy to the process of teacher education of early childhood education and to the organization of teaching work, considering its philosophical, psychological and pedagogical-didactic foundations. It presents the dialectical articulation of this theory with praxis. The methodology is bibliographic in nature and contemplates the assumptions of historical-dialectical Materialism and Historical-Critical Pedagogy from Marx (1984; 1985), Saviani (2000; 2008; 2011; 2013), Arce and Martins (2013), Marsiglia (2011), Colares (2011), Duarte (1999; 2007; 2016) and Pasqualini (2011). The results allow us to conclude that the foundations of Historical-Critical Pedagogy corroborate the planning and development of educational practice that considers the triad "recipient-content-form" with the valorization of the role played by the teacher of early childhood education to produce, intentionally, in each individual, the humanity that is constituted historically and collectively by human beings with the appropriation of cultural and socially produced knowledge.

Keywords: Historical-critical pedagogy. Teacher training. Early Childhood Education.

\section{CONTRIBUCIONES DE LA PEDAGOGÍA HISTÓRICO-JUICIOSA A LA FORMACIÓN Y ORGANIZACIÓN DEL TRABAJO DOCENTE EN LA EDUCACIÓN DE LA PRIMERA INFANCIA}

\section{RESUMEN}

El estudio consiste en comprender los aportes de La Pedagogía Histórico-Crítica al proceso de formación docente de la educación infantil y a la organización del trabajo docente, considerando sus fundamentos filosóficos, psicológicos y pedagógicos-didácticos. Presenta la articulación dialéctica de esta teoría con la praxis. La metodología es de carácter bibliográfico y contempla los supuestos del Materialismo histórico-dialéctico y la Pedagogía Histórico-Crítica de Marx (1984; 1985), Saviani (2000; 2008; 2011; 2013), Arce y Martins (2013), Marsiglia (2011), Colares (2011), Duarte (1999; 2007; 2016) y Pasqualini (2011). Los resultados nos permiten concluir que los fundamentos de la Pedagogía Histórico-Crítica corroboran la planificación y desarrollo de la práctica educativa que considera la tríada "receptor-contenido-forma" con la valorización del papel desempeñado por el maestro de educación infantil para producir, intencionalmente, en cada individuo, la humanidad que está constituida histórica y colectivamente por los seres humanos con la apropiación del conocimiento cultural y socialmente producido.

Palabras clave: Pedagogía histórico-crítica. Formación del profesorado. Educación Infantil.

\section{INTRODUÇÃO}

A formação docente e o trabalho pedagógico na educação infantil, independente da consciência que se tenha, são processos que se sustentam em teorias. Neste artigo objetivamos compreender as contribuições da 
Pedagogia Histórico-Crítica (PHC) ao processo de formação de professores em educação infantil e na organização do trabalho docente, a partir de seus fundamentos filosóficos, psicológicos e pedagógico-didáticos abstraindo-se dessa compreensão a articulação dialética desta teoria com a práxis e a necessária consciência de tais processos.

A formação de professores é um tema recorrente nos espaços de ensino e as contribuições da Pedagogia Histórico-Crítica são fundamentais para entender a concepção de ser humano, o desenvolvimento e o papel da escola, contrapondo-se aos padrões atuais que produzem 0 esvaziamento e a desvalorização destes profissionais e, consequentemente, da educação escolar (MARSIGLIA; MARTINS, 2013).

Destarte, Martins (2010, p. 28) assinala que a valorização docente exige o reconhecimento da "[...] formação e o trabalho do professor em toda sua complexidade, como fundamentalmente, condição para a plena humanização dos indivíduos, sejam eles alunos, sejam professores".

A teoria pedagogia histórico-crítica se propõe a realizar esse enfrentamento, à medida que apresenta no materialismo histórico dialético seu fundamento filosófico e percebe o papel da escola direcionado ao desenvolvimento humano. Daí a importância do aprofundamento reflexivo sobre esta teoria, sendo basilar para a organização do trabalho escolar, ampliação da concepção de mundo e para a prática da atividade educacional.

Nesse sentido, afirma Saviani (2000, p. 32):

[...] se não partirmos para um plano de emergência lúcido, corajoso, arrojado, que sinalize o empenho efetivo em reverter a situação de calamidade pública em que se encontra o ensino dos diferentes graus em nosso país, as proclamações em favor da educação não passarão de palavras ocas, acobertadoras da falta de vontade política para enfrentar o problema. E, nesse diapasão, avançaremos século XXI adentro, ampliando ainda mais o já insuportável déficit histórico que vem vitimizando a população brasileira em matéria de educação. 
Cabe enfatizar que na perspectiva desta Teoria, o ser humano em toda a sua constituição biológica não garante a efetiva humanização. Para se tornar humano precisa se apropriar daquilo que as gerações anteriores produziram, incorporaram e superaram num dado momento histórico e cultural. Assim, a produção e o acesso ao mundo da cultura só ocorrem por meio do trabalho. Santos e Nunes (2021, p.4) enfantizam que "o homem transforma a natureza em função de suas necessidades, resultando desse processo um mundo humano, o mundo da cultura". Conforme Marx (1984), o trabalho é atividade criadora e criativa, e que somente o ser humano consegue realizar, diferenciando-se de outras espécies, construindo suas relações com a sociedade e com outros indivíduos.

No contexto da educação, Saviani $(2011$, p. 13) corrobora esse sentido e complementa que o trabalho educativo: "[...] é o ato de produzir direta e intencionalmente, em cada indivíduo singular, a humanidade que é produzida histórica e coletivamente pelo conjunto dos homens". Dessa maneira, entende que da forma como os homens produzem sua existência provém o modo como se produz a educação, reportando-se explicitamente ao conceito de "modo de produção".

Portanto, para a Pedagogia Histórico-Crítica o trabalho educativo é uma atividade intencional, organizada, planejada e dirigida, conforme os objetivos e resultados educacionais que se pretendem alcançar. Percebemos que a apropriação desta teoria como processo de humanização transforma a concepção do que se deve propor na escola, uma vez que

[...] a sociedade produz o homem, mas também é produzida por ele. Assim, a consciência é uma abstração da vida real, sendo produto da atividade humana, daí admitir que não é a consciência que cria a vida, mas a vida que, sob condições sociais reais, cria a consciência (COLARES, 2011, p. 191).

O artigo é resultado de estudos bibliográficos de autores instituidores das teorias aqui discutidas, o Materialismo histórico-dialético e a Pedagogia Histórico-Crítica, sendo que contempla produções de Marx (1984; 1985), Saviani (2000; 2008; 2011; 2013). Arce e Martins (2013), Marsiglia (2011), 
Colares (2011), Duarte (1999; 2007; 2016) e Pasqualini (2011). Os itens e subitens que se seguem foram organizados de forma a possibilitar uma leitura iniciando pelos fundamentos das teorias e seguir para as questões do planejamento da prática pedagógica na educação infantil.

\section{FUNDAMENTOS DA PEDAGOGIA HISTÓRICO-CRÍTICA: AVANÇO E TRANSFORMAÇÃO DA CONCEPÇÃO DE MUNDO DE PROFESSORES E ALUNOS}

A Pedagogia Histórico-Crítica é uma teoria criada pelo Professor Dermeval Saviani, no final da década de 1970. Esta concepção surgiu com a finalidade de superar as teorias não-críticas, tais como a pedagogia tradicional, pedagogia nova e a pedagogia tecnicista, as quais "[...] encaram a educação como autônoma e buscam compreendê-la a partir dela mesma" (SAVIANI, 2007, p. 5). Também buscou superar as teorias críticoreprodutivistas, que viam a teoria do sistema de ensino como violência simbólica, e ainda a teoria da Escola como Aparelho Ideológico de Estado e a Teoria da Escola Dualista, as quais, segundo o referido autor, "[...] são críticas uma vez que se empenham em compreender a educação remetendo-a sempre a seus condicionantes objetivos, isto é, à estrutura socioeconômica que determina a forma de manifestação do fenômeno educativo" (SAVIANI, 2007, p. 5), mas embora críticas, não transformam a sociedade, pois não viam possibilidade de humanização pela via da escola.

Tais teorias reproduzem a desigualdade da sociedade, não viabilizam possibilidades de mudanças. É nesse contexto que o autor inicia a formulação da Pedagogia Histórico-Crítica, propondo uma transformação para que todos tenham acesso a uma educação de qualidade, tanto o burguês, quanto o trabalhador, com uma formação crítica e reflexiva. Cabe, então, à Pedagogia Histórico-Crítica "[...] a tarefa de superar tanto o poder ilusório (que caracteriza as teorias não-críticas) como a impotência (decorrente das teorias crítico-reprodutivistas)" (SAVIANI, 2007, p. 31).

Portanto, objetiva resgatar a valorização da escola, a reorganização do processo educativo, favorecer o diálogo entre os educandos e o professor com a cultura acumulada historicamente, considerando os seus 
interesses, os ritmos de aprendizagem e o desenvolvimento psicológico, a partir da sistematização lógica dos conhecimentos, para a transmissão e assimilação dos conteúdos. Num enfoque de contribuição, pode-se dizer que situa o professor em relação ao ato de ensinar e fornece subsídios teóricos que contribuem na prática docente.

A filosofia que embasa esta Teoria é o Materialismo Histórico-Dialético, desenvolvido por Marx e Engels. Fundamenta-se no modo humano de produção social da existência, isto é, na interpretação da realidade, na prática articulada à teoria, na concepção de mundo, de vida, na materialidade, na concreticidade, "[...] funciona como mediador no processo de entender a estruturação, o desenvolvimento e a transformação dos fenômenos sociais, dos objetos que investigamos" (COLARES, 2011, p. 190).

Em conformidade com Colares (2011), na perspectiva materialista histórica e dialética de Marx e Engels, só existirá a dialética se existir movimento e só haverá movimento se existir o processo histórico, quer seja da natureza, do ser humano e/ou do conhecimento, pois o universo e tudo o que nele existe, pode ser racionalmente conhecido e, por conseguinte, o conhecimento produzido pelo indivíduo deve buscar a reprodução do real, em suas múltiplas determinações.

Marx (1985) afirma que, para entendermos a evolução do indivíduo na sociedade, devemos estudar os fatos num contexto social. Isto é, por meio das relações estabelecidas com o outro junto à sociedade e pelas condições materiais envolvidas neste processo é que o ser humano reproduzirá sua existência.

[...] no caso da pedagogia histórico-crítica, uma de suas características fundamentais é que ela se posiciona claramente a favor dos interesses dos trabalhadores, isto é, da classe fundamental dominada na sociedade capitalista. Daí seu caráter de pedagogia contra hegemônica inserindo-se na luta pela transformação da sociedade atual (SAVIANI, 2013, p. 26).

Nesta perspectiva, a Pedagogia Histórico-Crítica se constitui em uma 
teoria que valoriza a socialização do conhecimento construído historicamente pelo conjunto dos seres humanos. Desta forma, a escola é vista como um espaço principal de apropriação e sistematização do conhecimento produzido pela humanidade no decorrer do percurso histórico e das relações estabelecidas em busca da transformação social. Assim, "a educação deve possibilitar que, através de um processo reflexivo e crítico, cada indivíduo reconstrua conscientemente seu pensamento" (THOMÉ, BRAGA e LAMEIRA, 2021, p. 6).

Newton Duarte (2016), em seu livro "Os conteúdos escolares e a ressurreição dos mortos", mais especificamente no capítulo b, defende a ideia de que a concepção de mundo é essencial para compreendermos o que diferencia a Pedagogia Histórico-Crítica de outras teorias pedagógicas e o que se almeja com esta teoria, com as suas proposições em termos de conhecimentos a serem socializados pela educação escolar e de formas de trabalhar nas escolas esses conhecimentos, para que as crianças, jovens e adultos, possam efetivamente realizar um processo de aprendizagem aprofundada, consistente, ou seja, de incorporação desses conhecimentos a sua vida, as suas atividades, a sua maneira de ver o mundo e a sua individualidade.

O autor evidencia o trabalho educativo como um processo de humanização dos indivíduos, sendo uma reprodução da humanização que vem sendo construída ao longo da história. A concepção de mundo a qual se vincula a pedagogia histórico crítica é o materialismo histórico dialético, portanto, é uma visão da natureza, da sociedade, das relações sociais, do conhecimento, da individualidade humana e do gênero humano. As características do gênero humano não são transmitidas pela herança genética, uma vez que não se acumulam no organismo humano, estas características são desenvolvidas no processo histórico, a partir da apropriação da natureza pelo indivíduo. Dessa maneira, o "gênero humano é uma categoria que expressa a síntese, em cada momento histórico, de toda a objetivação humana até aquele momento" (DUARTE, 1999, p.18).

Nesse viés, o autor assinala que a humanidade está vivendo um 
momento de grande difusão do negacionismo, que consiste em uma atitude contrária ao conhecimento e à razão, é uma atitude anticientífica, irracionalista, obscurantista. O negacionismo é parte de uma atitude mais ampla que é o obscurantismo. O obscurantismo não pode ser identificado com a ignorância, uma vez que, ignorar faz parte do processo de conhecimento da humanidade. A humanidade avança no conhecimento da realidade à medida em que se identifica aquilo que desconhece, ou seja, aquilo que ignora. Portanto, aquilo que ignora está no campo da ignorância.

Contudo, realizam-se esforços sistemáticos para que se possa conhecer o que antes não conhecia, aquilo que estava no campo da ignorância, passa para o campo do conhecido. À medida que se amplia o campo do conhecido, também se amplia o campo da ignorância do que ainda precisa ser conhecido. Surgem mais questões e assim avança o conhecimento. Então, há uma dialética histórica permanente entre ignorância e conhecimento. Entretanto, o obscurantismo é um esforço sistemático contra o avanço do conhecimento, contra a difusão do conhecimento, contra a verdade. É a luta sistemática para manter as pessoas na ignorância.

E o questionamento que a Pedagogia Histórico-Crítica nos permite fazer, é: Como enfrentar o obscurantismo? E a resposta também já nos foi dada pela PHC, pois a forma de enfrenta-lo é pela elevação cultural generalizada da população, pela difusão do conhecimento, pela forma como o ser humano compreende o mundo, a sociedade, a si mesmo, o outro, numa perspectiva de concepção de mundo que seja superior à burguesa, direcionada à valorização da dignidade da vida humana. Entende-se que "não é possível pensar a educação e, em especial, a educação na perspectiva da PHC, sem considerar a sociedade e a realidade existente" (ORSO, 2020, p. 4).

Assim, o conhecimento trabalhado na educação escolar deve ter por objetivo fazer avançar e transformar a concepção de mundo de professores e alunos, e não, unicamente atender às necessidades do cotidiano imediato 
das pessoas. Dessa forma, a visão de mundo precisa superar o senso comum, conceituado por Gramsci (1978) e elevar-se à consciência filosófica, em um movimento de transformação.

No contexto das bases teóricas que fundamentam a Pedagogia Histórico-Crítica é salutar compreender que:

[...] a tarefa central dos educadores que se colocam no campo do marxismo implica em um duplo e concomitante movimento: trata-se de empreender a crítica à educação burguesa evidenciando seus mecanismos e desmistificando sua justificação ideológica; ao mesmo tempo, cabe realizar o segundo movimento que implica reorganizar a prática educativa de modo a viabilizar, por parte das camadas dominadas à frente o proletariado, o acesso ao saber elaborado. Esse acesso significa a apropriação dos conteúdos sistematizados dos quais os trabalhadores necessitam para potencializar sua luta em defesa de seus interesses contra a dominação burguesa (SAVIANI, 2009, p. 114-115).

Além do compromisso com uma prática transformadora, como educadores têm-se uma dupla tarefa: de um lado, empreender profunda crítica à educação burguesa, evidenciando seus mecanismos classistas de funcionamento, desmitificando a inculcação ideológica presente nas escolas; por outro, organizar uma prática educativa que propicie aos assalariados, o acesso ao saber historicamente produzido pela humanidade, possibilitando uma potencialização de sua luta em defesa de seus interesses, uma vez que "a burguesia se apropria da ciência e de todos os saberes para impulsionar o desenvolvimento das forças produtivas sob seu controle, bem como para reforçar e naturalizar a dominação de classe" (LOMBARDI, 2010, p. 40-41).

O conteúdo da concepção pedagógica burguesa tem sido analisada por Newton Duarte em uma acentuada crítica ao que este autor tem denominado de "pedagogias do aprender a aprender", as quais apresentam perspectivas ideologicamente ligadas ao neoliberalismo, incluindo ainda o escolanovismo, construtivismo, a pedagogia das competências, a pedagogia dos projetos, a pedagogia do professor 
reflexivo, dentre outras (DUARTE, 2000a; 2000b; 2003).

Nesse sentido, Dermeval Saviani (2008), no terceiro capítulo do livro "Escola e democracia", intitulado "Escola e democracia II Para além da teoria da curvatura da vara", apresenta na forma de momentos os pontos de partida da Pedagogia Histórico-Crítica, visto à interdependência entre estes, em contraponto à forma de "passos" do método tradicional e o escolanovista. Conforme o autor, é necessário:

[...] levar em conta que o empenho em apresentar simetricamente aos cinco passos de Herbart [pedagogia tradicional] e de Dewey [pedagogia nova] as características do método pedagógico que, no meu entendimento, se situa para além dos métodos novos e tradicionais, correspondeu a um esforço heurístico e didático cuja função era facilitar aos leitores a compreensão do meu posicionamento. Em lugar de passos que se articulam numa sequência cronológica, é mais apropriado falar aí de momentos articulados num mesmo movimento, único e orgânico (SAVIANI, 2008, p. 59-60).

Com base nos estudos de Saviani, a autora Marsiglia (2011), explana como ocorre a organização proposta pela pedagogia histórico-crítica para esses momentos, a iniciar pela:

a) Prática social: como ponto de partida para a prática educativa. Nesse primeiro momento, o professor domina os conteúdos de ensino e tem experiências em relação à pratica social. Contudo, seu conhecimento é limitado, pois ainda não tem clareza do nível de compreensão dos educandos. Nesse sentido, Saviani (2008) destaca que é necessário considerar a compreensão sincrética dos alunos em relação à prática social, uma vez que possuem domínios fragmentados, sem estabelecer relações que formam a totalidade, por conseguinte, deve-se entender que o trabalho educativo não consiste em concentrar esforços no que o aluno já consegue fazer por si mesmo, mas o que consegue fazer na relação com o professor. $E$ essa relação dialética entre os saberes dos educadores e educandos define o ponto de partida da prática educativa.

b) Problematização: o professor deve apresentar aos seus alunos os 
motivos pelos quais esse ou aquele conteúdo estão presentes no planejamento. Dessa maneira, a problematização deve conduzir o educando ao conhecimento proveniente das relações do cotidiano (conhecimento fragmentado) para o conhecimento científico, que deve ser oferecido na escola, reestruturando-se o domínio sobre as questões da prática social. E para isso, o professor precisa alicerça-se na forma como orientará o desenvolvimento da aprendizagem, embasando-se nos seus objetivos de ensino.

c) Instrumentalização: é o momento em que os "alunos devem apropriar-se dos instrumentos culturais produzidos pela humanidade; instrumentos esses que garantem aos indivíduos participarem da sociedade de forma qualitativamente superior" (MARSIGLIA, 2011, p. 33), a partir dos conteúdos instrumentalizados pelo ato educativo do professor. Assim, o estudante poderá dar respostas à problematização apresentada.

d) Catarse: considerado o momento culminante do processo educativo, que ocorre quando o aluno apreende o fenômeno de forma mais complexa, é a etapa "[...] que se efetiva enquanto superação da heterogeneidade da vida cotidiana [...]" (DUARTE, 2007, p. 61), isto é, há uma transformação e a aprendizagem se concretiza. Nesta etapa, a relação com o conhecimento se torna intencional e consciente, em um movimento dinâmico e dialético.

e) Ponto de chegada da prática educativa (prática social modificada): o estudante, tendo adquirido e sintetizado o conhecimento, possui o entendimento e senso crítico para alcançar seus objetivos de maneira transformadora, elaborada, pensada e problematizada. Segundo Marsiglia (2011, p. 34), "quando o aluno problematiza a prática social e evolui da síncrese para a síntese, está no caminho da compreensão do fenômeno em sua totalidade".

Diante do exposto em busca de compreender os fundamentos da pedagogia histórico-crítica torna-se relevante elucidar que para utilizar a teoria coerentemente com seus postulados é necessário que o educador observe os resultados provenientes de suas práticas e que busque dominar o 
que os detentores dos meios de produção dominam, de forma a contribuir para a luta pela superação da condição de exploração (SAVIANI, 2008).

\section{REFLEXÕES DA PEDAGOGIA HISTÓRICO-CRÍTICA PARA A PRÁTICA PEDAGÓGICA DO PROFESSOR NA EDUCAÇÃO INFANTIL}

Para a pedagogia histórico-crítica, o professor, e também o da educação infantil, é elemento fundamental no processo educativo, pois é por meio desse profissional que a relação ensino e aprendizagem pode ser transformadora. O desenvolvimento social e histórico dos indivíduos só se concretiza através da colaboração com o outro, sendo o professor este outro qualificado para realizar a mediação entre o estudante e o conhecimento desenvolvido socialmente (MARSIGLIA; MARTINS, 2013).

É importante considerar que "a criança sobre a qual incide a educação é um ser histórico-social" (ARCE; MARTINS, 2013, p. 59). Isto significa que a criança só poderá dotar-se dos atributos especificamente humanos se for oportunizado um processo educativo para que esta se aproprie dos conhecimentos da humanidade. Nessa perspectiva, percebese a relevância da instituição escolar no desenvolvimento da criança, sendo um lugar propício para a realização de práticas pedagógicas que viabilizam a aprendizagem dos sujeitos. Corroborando com esse pensamento, Silva, Machado e Pacífico (2018, p.117) anunciam que "entender o espaço escolar como fonte de pesquisa permite aos profissionais a reflexão e produção de conhecimentos pautados em suas ações pedagógicas".

Assim, a tarefa a que se propõe a pedagogia histórico-crítica em relação à educação implica:

a) Identificação das formas mais desenvolvidas em que se expressa 0 saber objetivo produzido historicamente, reconhecendo as condições de sua produção e compreendendo suas principais manifestações, bem como as tendências atuais de transformação.

b) Conversão do saber objetivo em saber escolar, de modo que se torne assimilável pelos alunos no espaço e tempo escolares.

c) Provimento dos meios necessários para que os alunos não 
apenas assimilem o saber objetivo enquanto resultado, mas apreendam o processo de sua produção, bem como as tendências de sua transformação (SAVIANI, 2013, p. 8).

Importante destacar que a Psicologia Histórico-Cultural é o fundamento psicológico da Pedagogia Histórico-Crítica. Lev Vigotski é o propulsor das bases teóricas da Psicologia Histórico-Cultural, foi marxista e estudioso de filosofia e literatura. Estava convicto da necessidade de formação de um novo ser humano para a sociedade mais livre que estava em construção, dentro do princípio revolucionário de se organizar socialmente de forma mais humana, produzindo não para a acumulação de capital, mas para as necessidades e o desenvolvimento pleno dos seres humanos.

Segundo Vigotski (2004), é por intermédio das interações com o meio, com o outro e com os objetos que o sujeito desenvolve as funções psíquicas superiores que diferem os seres humanos dos demais animais, tais como a memória voluntária, o pensamento, a linguagem, a atenção, a percepção, as emoções, os sentimentos, a função simbólica da consciência, o controle da vontade e a imaginação. Para o autor, a origem da conduta consciente é inicialmente externa ao indivíduo, está nas relações humanas mediadas por instrumentos.

O instrumento medeia e controla a ação humana voluntária sobre o mundo, sobre os outros e sobre si mesmo. Por exemplo: Se entregar uma colher na mão de uma criança, que ainda não conhece a função ou o significado desse objeto, o simples fato dela manusear o objeto e ter qualquer tipo de interação com o objeto não permitirá a ela compreender a função desse objeto e usá-lo da forma como este foi culturalmente pensado. Então, para que a criança use a colher, esta vai ter que adaptar os seus movimentos ao seu uso. Portanto, a função e o significado dos instrumentos estão na cultura e precisam ser ativamente internalizados pelo indivíduo nas relações sociais. É um raciocínio semelhante ao que Marx (1985) faz em relação à Teoria do Valor, quando diz que o valor do diamante não está no diamante, mas no trabalho socialmente necessário para produzi-lo. 
Para a Psicologia Histórico-Cultural a escola enquanto instituição social é fundamental ao desenvolvimento psíquico da criança por sua função e representatividade na sociedade, pois

[...] as aquisições do desenvolvimento histórico das aptidões humanas não são simplesmente dadas aos homens nos fenômenos objetivos da cultura material e espiritual que os encarnam, mas são aí apenas postas. Para se apropriar destes resultados, para fazer deles as suas aptidões, "os órgãos da sua individualidade", a criança, o ser humano, deve entrar em relação com os fenômenos do mundo circundante através de outros homens, isto é, num processo de comunicação com eles. Assim, a criança aprende a atividade adequada. Pela sua função este processo é, portanto, um processo de educação (LEONTIEV, 1978, p. 272).

Nesse contexto, sem o contato da criança com a cultura e com as gerações mais velhas, o despertar das necessidades e aptidões humanas não acontecerá, pois é o aprendizado que possibilita o despertar da capacidade de falar, de ouvir, de perceber as cores, as formas, os sons, os números, de pensar, de refletir, de raciocinar, de emocionar-se, da aptidão para a leitura, escrita, entre outros. Assim, "o papel da educação é garantir a criação de aptidões que são inicialmente externas aos indivíduos, dadas como possibilidades incorporadas nos objetos da cultura" (MELLO, 1999, p. 19).

Essas relações de aprendizagem permitem refletir sobre a necessidade de acesso dessas novas gerações à cultura e às qualidades humanas historicamente desenvolvidas e acumuladas, isto é, a linguagem, a ciência, controle da própria conduta, a memória, os costumes, os hábitos, os instrumentos, a dança, o teatro, a música, a filosofia, dentre outras. Percebese, então, a relevância do papel do professor, da família, do meio, dos outros seres, dos objetos e da escola neste processo de formação de desenvolvimento de consciência e atribuição de sentidos das crianças, de acordo com a função social para a qual foram criadas. Essas aquisições humanas não são herdadas biologicamente, mas permanecem sob a forma de objetos externos da cultura material e intelectual (MELLO, 2007). 
Em muitas práticas educativas destinadas às crianças percebe-se a necessidade de diversificar as atividades propostas em um outro ambiente da escola, de forma que a criança não permaneça o tempo todo sentada na cadeira, realizando as tarefas de registro do livro didático, por exemplo. Esse fato evidencia que a criança precisa conviver, conhecer, buscar novas experiências e estar na presença de outras pessoas, objetos e espaços.

Nessa perspectiva, muitas vezes, as crianças ocupam o lugar apenas de receptores do saber provenientes do conhecimento mediado pelo professor, submetendo-se à hierarquia das escolas para o cumprimento dos objetivos institucionais atrelados em considerável medida à rotina dos afazeres diários e o tempo para a execução de tarefas.

Destaca a autora Zuquieri $(2007$, p. 50) que:

As práticas pedagógicas, nesta faixa etária, devem orientar-se, levando em conta a criança como um ser social, que possui uma história de vida e é influenciada pelo meio. Desse modo, a Educação Infantil deve propiciar, através de sua organização, um ambiente de crescimento, para que a criança desenvolva suas capacidades num processo contínuo de conhecer.

Acentua-se que no processo de aprendizagem cada criança apresenta um tempo peculiar para concluir determinada atividade, pois o ser humano possui esquemas de desenvolvimento diferenciados. Logo, as propostas pedagógicas devem considerar a criança como o centro do planejamento curricular, respeitando ritmos, desejos e potencialidades.

Torna-se problemático ao desenvolvimento infantil a busca, por parte do professor, em cumprir determinada atividade prescrita na rotina, sem considerar as especificidades humanas, biológicas, intelectuais, sociais, culturais, motoras e físicas de cada ser. Portanto, ao elaborar as atividades propostas se deve refletir sobre o trabalho pedagógico a partir da compreensão de como as crianças se desenvolvem e aprendem.

Vigotski (2004) evidenciou que a criança aprende desde o nascimento e o desenvolvimento infantil envolve um processo complexo a partir de uma 
lógica interna de condicionamento mútuo e dialético com o mundo que o cerca. Compreende, ainda, que os seres humanos necessitam de uma atividade intencional e do trabalho para firmar a existência humana.

Para Marsiglia e Martins (2015, p. 18-19),

[...] ao propor a necessária integração dos conteúdos de formação operacional e de formação teórica, cabe à escola de educação infantil disponibilizar aos bebês e às crianças pequenas as máximas objetivações culturais já alcançadas historicamente.

Mas, para as autoras, para a efetivação da práxis, cabe ao docente "[...] assumir seu lugar de representante das mesmas, isto é, sua condição de portador do universo de significações científicas que o torna profissional em sua área de atuação". Ele não deve abrir mão de seu lugar de mediador de um desenvolvimento, que segundo as autoras, é o "[...] desenvolvimento intencionalmente projetado à superação das conquistas espontâneas, fortuitas e casuais promovidas também pelas esferas da vida cotidiana" e que é materializado a partir da tríade "destinatário-conteúdo-forma", sendo:

[...] quando então o trabalho pedagógico orienta-se pelo conhecimento acerca das características que a criança já dispõe na contraposição àquelas que ainda não existem mas visamos formar; toma como ponto de partida os conhecimentos que a criança já possui e articula-os àquilo que ela não domina - mas deve dominar; elegendo procedimentos e recursos que se firmam como práxis educativa, isto é, como ineliminável articulação entre teoria e prática (MARSIGLIA; MARTINS, 2015, p. 18-19).

Assim, as propostas pedagógicas das instituições devem possibilitar condições para o trabalho coletivo e organização de materiais, espaços e tempos que assegurem: a indivisibilidade das dimensões motoras, afetivas, cognitivas, sociais, culturais, entre outras; a participação e diálogo com as famílias; gestão democrática entre a comunidade local; a promoção de vivências entre crianças de mesma e diferente idade; os deslocamentos nos espaços internos e externos à escola; a acessibilidade de espaços e 
materiais e apropriação das contribuições histórico-social-cultural da humanidade (BRASIL, 2009).

\section{CONSIDERAÇÕES FINAIS}

Com base nos pressupostos teóricos abordados neste artigo, que fundamentam o ensino e aprendizagem sob a perspectiva da Pedagogia Histórico-crítica, é possível concluir que esta defende a importância do trabalho educativo para produzir de maneira intencional, em cada indivíduo, a humanidade que é constituída histórica e coletivamente pelos seres humanos, a partir da apropriação do conhecimento.

Evidencia-se, então, a importância do papel exercido pelo professor de educação infantil, sendo necessário entender que este profissional é "alguém que transmite à criança os resultados do desenvolvimento histórico, medeia o processo de apropriação dos objetos culturais e organiza a atividade da criança" (PASQUALINI, 2011, p. 76).

Dessa maneira, a educação escolar deve possibilitar aos educandos sua participação na sociedade de forma crítica, superando a visão de senso comum. Assim, considera-se que a teoria pedagogia histórico-crítica colabora significantemente para a superação de práticas pedagógicas estanques e repetitivas na educação infantil, buscando uma educação transformadora e emancipadora da criança.

Diante dessas considerações, surge o desafio de buscar implementar o ensino na educação infantil embasado nesta teoria. A exemplo, Marsiglia (2011), realizou uma intervenção relatada em seu livro intitulado "A Prática Pedagógica Histórico-Crítica na educação infantil e ensino fundamental", no qual relata como ocorreu sua pesquisa e intervenção, explicitando a possibilidade de embasar a prática educativa nessa etapa da educação, na metodologia proposta pela pedagogia histórico-crítica.

Deste modo, esta teoria surge como fundamentação basilar para orientar o pensar e agir docentes, numa perspectiva que considera a criança na condição de sujeito em atividade, em um movimento dinâmico e dialético, compreendendo a necessidade de estabelecimento de uma 
relação de comunicação entre o professor, as crianças e a história socialmente constituída.

Com essa compreensão é possível redimensionar o trabalho pedagógico a partir da concepção de criança como sujeito que aprende como alguém que estabelece relações, imagina, pensa, cria, sente, dialoga, resolve problemas, avalia, planeja e controla seu próprio comportamento. E, nesse processo de aprendizagem necessita de parceiros mais experientes para que as interações e descobertas contemplem possibilidades máximas de desenvolvimento.

Assim, as reflexões propostas pela Pedagogia histórico-crítica buscam propor múltiplos caminhos para se pensar e se fazer a educação, para que a crítica não seja esvaziada pela falta de soluções e organização metodológica do pensamento. Assim, a educação escolar se apresenta com potencialidade de desenvolver a transformação do saber sistematizado em saber escolar científico e para obter essa função social da escola, necessita-se de uma formação dos professores baseada nesta teoria.

\section{REFERÊNCIAS}

ARCE, A.; MARTINS, L. M. (org.). Quem tem medo de ensinar na educação infantil: em defesa do ato de ensinar. 3. ed. Campinas, SP: Alínea, 2013.

BRASIL. Diretrizes Curriculares Nacionais para a Educação Infantil (DCNEI). Resolução n 5, de 17 de dezembro de 2009.

COLARES, A. A. História da Educação na Amazônia. Questões de Natureza Teórico-metodológicas: críticas e proposições. In: Revista HISTEDBR On-line, Campinas, número especial, p. 187-202, out. 2011.

DUARTE, N. A individualidade para si: contribuição a uma teoria históricosocial da formação do indivíduo. Campinas, SP: Autores Associados, 1999.

DUARTE, N. Vigotski e o Aprender a Aprender: críticas às apropriações neoliberais da teoria vigotskiana. Campinas: Autores Associados, 2000a.

DUARTE, N. (org.). Sobre o Construtivismo: contribuições a uma análise crítica. Campinas: Autores Associados, 2000b. 
DUARTE, N. Sociedade do Conhecimento ou Sociedade das llusões?

Campinas: Autores Associados, 2003.

DUARTE, N. Educação escolar, teoria do cotidiano e a escola de Vigotski. 4. ed. Campinas-SP: Autores Associados, 2007.

DUARTE, N. Os conteúdos escolares e a ressurreição dos mortos: contribuição à teoria histórico-crítica do currículo. Campinas: Autores Associados, 2016.

GRAMSCl, A. Concepção Dialética da História. Trad. Carlos N. Coutinho. Rio de Janeiro: Civilização Brasileira, 1978.

LEONTIEV, A. O desenvolvimento do psiquismo. Lisboa: Livros Horizonte, 1978.

LOMBARDI, J. C. Educação e ensino em Marx e Engels. Germinal: Marxismo e Educação em Debate, Londrina, v. 2, n. 2, p. 20-42; ago. 2010. Disponível em: https://periodicos.ufba.br/index.php/revistagerminal/article/view/9581/7005. Acesso em: 17 jun. 2021.

MARSIGLIA, A. C. G.; MARTINS, L. M. Contribuições para a sistematização da prática Pedagógica na educação infantil. Cadernos de Formação RBCE, p. 15-26, mar. 2015. Disponível em:

http://www.revista.cbce.org.br/index.php/cadernos/article/viewFile/2079/10 35. Acesso em: 16 ago. 2021.

MARSIGLIA, A. C. G.; MARTINS, L. M. Contribuições da Pedagogia HistóricoCrítica para a Formação de Professores. Germinal: Marxismo e Educação em Debate, Salvador, v. 5, n. 2, p. 97-105, dez. 2013. Disponível em: https://periodicos.ufba.br/index.php/revistagerminal/article/view/9702/7090. Acesso em: 07 jun. 2021.

MARSIGLIA, A. C. G. Um quarto de século de construtivismo como discurso pedagógico oficial na rede estadual de ensino paulista: Análise de programas e documentos da Secretaria de Estado da Educação no período de 1983 a 2008. 2011. Disponível em:

https://repositorio.unesp.br/bitstream/handle/11449/101577/marsiglia_acg_dr _arafcl.pdf? sequence=1 \&isAllowed=y. Acesso em: 13 jun. 2021.

MARSIGLIA, A. C. G. A prática pedagógica histórico-crítica na educação infantil e ensino fundamental. Campinas, SP: Autores Associados, 2011. (Coleção Educação contemporânea).

MARTINS, L. M. O legado do século XX para a formação de professores. In: MARTINS, L. M.; DUARTE, N. (orgs.). Formação de professores: limites contemporâneos e alternativas necessárias. São Paulo: Cultura Acadêmica, 2010. 
MARX, K. Manuscritos econômico-filosóficos de 1844. In: FERNANDES, F. (Org.) Marx e Engels: história. 2.ed. São Paulo: Ática, 1984.

MARX, K. O Capital: crítica da economia política. Tradução por Regis Barbosa e Flávio R. Kothe. São Paulo: Abril Cultural, 1985. Livro 1, v.1, t.1. (Os economistas).

MELLO, S. A. Infância e humanização: algumas considerações na perspectiva histórico-cultural. Perspectiva, Florianópolis, v. 25, n. 1, 83-104, jan./jun. 2007.

MELLO, S. A. Algumas implicações pedagógicas da Escola de Vygotsky para a Educação Infantil. Pro-Posições, v. 10, n. 1, mar.1999.

ORSO, P. J. O novo coronavírus, a pedagogia histórico-crítica, a sociedade de classes e o internacionalismo proletário. Revista Exitus, [S. I.], vol. 10, p. 01 54, 2020. DOI: 10.24065/2237-9460.2020v10n1ID1432. Disponível em: http://www.ufopa.edu.br/portaldeperiodicos/index.php/revistaexitus/article/ view/1432/849. Acesso em: 18 dez. 2021.

PASQUALINI, J. C. A educação escolar da criança pequena na perspectiva histórico-cultural e histórico-crítica. In: MARSIGLIA, A. C. G. (org.). Pedagogia histórico-crítica: 30 anos Campinas, SP: Autores Associados, 2011. (Coleção memória da educação).

SANTOS, M. C. dos; NUNES, K. de C. S. Currículo e saber objetivo na organização do ensino nas salas multisseriadas. Revista Exitus, [S. I.], vol. 11, p. 01 - 25, 2021. DOI: 10.24065/2237-9460.2021v11n1ID1564. Disponível em: http://www.ufopa.edu.br/portaldeperiodicos/index.php/revistaexitus/article/ view/1564/1014. Acesso em: 18 dez. 2021.

SAVIANI, D. Educação brasileira: estrutura e sistema. Campinas: Autores Associados, 2000.

SAVIANI, D. Escola e Democracia. 39. ed. Campinas: Autores Associados, 2007.

SAVIANI, D. Escola e Democracia. Campinas-SP: Autores Associados, edição comemorativa, 2008.

SAVIANI, D. Modo de produção e a pedagogia histórico-crítica. Germinal: Marxismo e Educação em Debate, Londrina, v. 1, n. 1, p. 110-1 16, jun. 2009. Disponível em:

http://www.vel.br/revistas/vel/index.php/germinal/article/view/2649/2303. Acesso em: 13 jun. 2021.

SAVIANI, D. Pedagogia histórico-crítica: primeiras aproximações. $11 . e d$. 
Campinas: Autores Associados, 2011.

SAVIANI, D. A pedagogia histórico-critica, as lutas de classe e a educação escolar. In: Germinal: Marxismo e Educação em Debate, Salvador, v. 5, n. 2, p. 25-46, dez. 2013.

SILVA, H. M. da; MACHADO, E. M. A.; PACÍFICO, J. M. O protagonismo do coordenador pedagógico na formação docente: experiência na Educação Infantil em Ji-Paraná-RO. Revista Exitus, [S. I.], v. 8, n² 2, p. 111 - 136, 2018. DOI: 10.24065/2237-9460.2018v8n2ID531. Disponível em:

http://educa.fcc.org.br/pdf/exitus/v8n2/2237-9460-exitus-8-2-1 11 .pdf. Acesso em: 18 dez. 2021.

THOMÉ, Z. R. C.; BRAGA, G. de B.; LAMEIRA, I. D. E. D. A formação do professor e seu reflexo na práxis educativa. Revista Exitus, [S. I.], vol. 11, p. 01 -22, 2021. DOI: 10.24065/2237-9460.2021v1 ln IID1714. Disponível em:

http://www.ufopa.edu.br/portaldeperiodicos/index.php/revistaexitus/article/ view/1714/1052. Acesso em: 18 dez. 2021.

VIGOTSKI, L. S. Teoria e método em psicologia. São Paulo: Martins Fontes, 2004.

ZUQUIERI, R. de C. B. Ensino de ciências na educação infantil: análise de práticas docentes na abordagem metodológica da pedagogia históricocrítica. Dissertação de Mestrado. Bauru: Faculdade de Ciências - UNESP, 2007.

Recebido em: 01 de novembro de 2021.

Aprovado em: 20 de dezembro de 2021 .

Publicado em: 20 de dezembro de 2021. 